\title{
Modernitenin Kadınları: Dandizetteler
}

\author{
Züleyha Çubuk ${ }^{1}$
}

\begin{abstract}
$\ddot{O} z$
'Kadın dandy' olarak bilinen dandizette, modernitenin 'kadın' kahraman imgesi olarak on sekizinci yüzyıl sonlarında gündelik yaşamda boy göstermeye başlamıştı. Dandizetteler ortaya çıktıklarında, yaşam tarzları ve radikal duruşlarlyla yerleşik kadın imgesini kökten değisştirdiler. Dandizetteler, dandylerle birlikte velya tek başlarına kültürel ve estetik üretimin merkezinde yer aldılar. Bu bildiride, kurgu becerileri ve marjinal kimlikleri ile dandizettelerin hayatı nasıl adeta bir drama icra eder gibi yaşadıkları anlatılacaktır.
\end{abstract}

Anahtar Sözcükler: Drama, Kadın, Kahraman, Dandizette, Modernite, Sanat.

\section{Modernity Women: Dandizettes}

\begin{abstract}
The dandizette, known as 'woman dandy', had begun to put in an appearance as the simulacrum of the heroine of modernity in everyday life in the late eighteenth century. As they occured, the dandizettes radically changed the entrenched woman simulacrum with their life-styles and radicalstances. The dandizettes took part in the origin of the cultural and aesthetic production with the dandies and/or on their own. In this paper, it is going to be told the dandizettes' how almost they lived like they performed a drama with their editings kills and marginalidentities.
\end{abstract}

Keywords: Drama, Woman, Heroine, Dandizette, Modernite, Art.

\section{Giriş}

Modernite, yeni toplumsal düzen tasarımını hayata geçirecek kahramanlara ihtiyaç duymuştur. On sekizinci yüzyılın sonlarında İngiltere' de ortaya çıkan, daha sonra modernitenin kahraman kültüne dönüşen dandylerin kadın çağdaşları olan dandizetteler, yeni toplumsal düzenin ihtiyaç duyduğu, onu her yönüyle deneyimleyecek ve deneyimini bir model olarak kitlelere sunabilecek kahraman tasavvurlarından biridir. Farklı kaynaklarda 'danydess', 'dandilly', 'dandysette' ve 'dandisette' olarak da tanımlanan "dandizette” terimi 1811-1820 dolaylarında tarih sahnesine çıkan ve çıktığı dönemde efemine züppe erkek figürü olarak mimlenen dandynin kadın formunu tanımlamak amaciyla kullanılmıştır. Kadınlığa özgü bir terimi ifade eden "dandizette"in kavramsallaşma süreci dandyden bağımsız gerçekleşememiştir. Bu nedenle "dandizette"i anlamak için modern çağın kahraman kültü dandylere kısaca değinmek gerekir.

Dandy, George Bryan Brummell (1778-1840)'in İngiltere'de kendi uygulamalariyla geliştirdiği yeni bir giyim tarzı ve tavır estetiğinin imgesel karşılığıdır. Sözcük olarak dandynin, Kral VII. Henry (1457-1509) tarafından bastırılan ve adına "dandiprat" denilen, değeri düşük, küçük, gümüş bir sikkeden türetildiği bilinmektedir (Van Dooren, 2012). Londra konuşma ağzına ait olan "dandy" ibaresi, zamanla 1813-1816 dolaylarında seçkin veya züppe dönemini anlatmak için kullanılmaya başlanmıştır. Dandy, çağdaş İngilizcede ise; "tüm zamanını ve parasını, giysileri ve dış görünüşü için harcayan eski moda bir adam” ve "biraz gülünç bir şekilde sık sık kullanılan" (Longman, 2005)² olarak tanımlanır.

1 Öğretim Görevlisi, Ordu Üniversitesi Müzik ve Sahne Sanatları Fakültesi, E-posta: zuleyhacubuk@gmail.com

2 Özel olarak belirtilmediği sürece, İngilizceden yapılan çevirilerin tamamı bildirinin sahibine aittir. 
Dandynin ortaya çıkışı, Avrupa'da monarşilerin iktidarda olduğu, sosyal sınıfların keskin hatlarla birbirlerinden ayrıldığ 1 ve aristokrasinin doruktan düşüşe geçtiği bir döneme denk gelir. Gelenek ile modern arasında yaşanan çelişkilerin birer ürünü olarak İngiliz aristokrasisinin geri dönülmez biçimde gücünü yitirdiği on sekizinci yüzyılın sonlarında ortaya çıtıktan sonra kısa sürede kültürel bir fenomen haline gelen dandy, Fransız Devrimi'yle birlikte moderniteye karşı estetik bir başkaldırı hareketine dönüşmüştür. Dandyler, özellikle İngiltere ve Fransa'daki uygulamalarla modernitenin arayış içinde olduğu yeni bir tür kahraman imgesi yaratmış; bu yönleriyle sanatın da ana malzemelerinden biri olmuşlardır.

Dandylerin ortaya çıktığı zaman dilimi, kavram olarak dandyliğin modernlikle birlikte anılmasına yol açmıştır. Modernlik, özellikle Batı Avrupa'da on yedinci yüzyılda meydana gelen teknolojik birikim ve ekonomik büyümeyle toplumları kurumsal ve kültürel bir değişim sürecine sokmuş; böylece etkileri dünya genelinde görülen yeni bir yaşam tarzı ve sosyal örgütlenme biçimi meydana getirmiştir. Modern çağın Batı Avrupa toplumlarında, özellikle İngiltere ve Fransa'da, yüksek sosyete arasında moda halini alan, daha sonra entelektüel kesime yayılan kişisel zarafet ve kibarlık estetiği üreten dandyler en iyi kıyafetleri giymiş, kendilerini ince sanatın çocukları olarak takdim etmiş ve kamusal alanlarda sıklıkla boy göstermişlerdir. Dandylerin çağında "Modern olmak, tarihsel gelenek ve dişsal otoriteler karşısında bir özerklik talep etmek, kendi inançlarını ve hayatını düzenleme hakkı elde etmek" (Küçük, 1994, s.206) demektir. Dandyler, yaşam tarzları ve estetik üretimleri ile modern çağın aradığı, geleneğe karşı modern zamanları yaşayacak, soluyacak, geleneksel sanatlara karşı modern sanatı besleyecek bir damar oluşturmuştur.

Dandy imgesi neden modernite için bir kahraman kültü olarak belirmiştir? Yaşar Çabuklu bu soruya şu sözlerle yanıt verir: Burjuvazi giyim kuşama ve kibarlığa ilişkin kendi estetik normlarını oluşturacak bir konumda değildi; ne aristokratlar gibi giyinebiliyor ne de ulus ölçeğinde bir < giyimsel eşitlik> sağlayabiliyordu. İlk modern dandi olan İngiliz George Bryan "Beau” Brummell (17781840) aristokratik bir kökene sahip değildi. Ancak Brummell özenli giyimi, etkileyici hal ve tavrı, elit sınıflara özgü yaşam tarzı ve sosyal manevra kabiliyeti sayesinde soylu kesimle yakın ilişkiler kurmuş, Prens Regent'le yakın arkadaş olmuştu. Brummell çok pahalı ve gösterişli elbiseler yerine son derece sade, koyu renkli elbiseler giyiyordu. Ancak giysilerinin kumaşı sade ve mükemmeldi. Elbisesi vücuduna tam olarak oturuyordu. Brummell hem vücudunun hem de elbisesinin temizliği konusunda son derece titizdi ve her zaman traşlıydı. Stile ilişkin bir tür züppelik yaratan Brummell, saf bir erkek şıklığı idealini temsil etmekteydi (Çabuklu, 2008, s.55-56).

İngiltere'de ilk dandy olarak kabul edilen George Bryan Brummel'in yaşam tarzı ve tavır estetiği ile temsil ettiği pür dandy imgesi, aristokrasinin gösteriş ve şatafat merakı ile yaşamlarını şekillendiren İngiliz sosyetesine sade giyinmeyi, soğukkanlılığı ve ağırbaşlı olmayı öğretmiştir. Brummell böylece, modanın, gösterişli sergi ve zenginlikle dayatıldığ 1 bir aristokrasiye yeni bir beğeni ve kısıtlama etiği getirmiştir. Restorasyon dönemi de dâhil, Brummell'e kadar İngiliz aristokrasisindeki hâkim züppelik (snobbism) olgusu, salt bu sınıfa özgü bir olgu iken; Brummell'in çizdiği dandy tipolojisi, snobluk olgusundan öte İngiliz toplumu için bir yeniliktir. Sınıfsal bir olgu olan züppelik, Restorasyon dönemi komedyalarında çizilen züppe tiplerle kendine bir temsil alanı bulurken, Brummell'in pür dandy imgesi modern zamanların kült kahramanı olduğunu, modernitenin ürettiği yeni bir estetik biçim olan romanlar vasıtasıyla ilan etmiştir. Örneğin 18201830 yılları arasında yazılan, ilk defa William Hazlitt'in Dandy Okulu (TheDandy School) (Hazzlit, 
1934, s.147) makalesinde ifade ettiği, "gümüş çatal romanları" (silverforknovels) ya da "şı roman" (fashionablenovel) olarak da adlandırılan dandy romanlarındaki züppe tipleri, Brummell'in dandy imajından esinlenilerek yaratılmıştır (Anonim, 2012).

Lord Byron, İngiliz dandyliğinde önemli bir yere sahiptir. Gerek İngiliz gerekse dünya edebiyatlarında en benmerkezci eser üreten isimlerden biri olan Lord Byron, Brummell ile aynı dönemde, Naiplik dönemi İngiltere'sinde yaşamıştır. Brummell'den tek fark1, İngiliz aristokrasisi içinde doğmuş ve yetişmiş olmasıdır. Sosyal yaşamında kendine bir tür "kader mahkûmu dandy" (doomeddandy) (Van Dooren, 2012, s.88) kimliği yaratmış olan Lord Byron, kendi edebiyatının başkahramanlarını, lirik-romantik dandy imgesi ile şekillendirmiştir. Mîna Urgan, Lord Byron'ın kendi kişiliğini ya da kendi kişiliği olarak benimsenmesini istediği belirli bir tipi her şiirinde işleyerek, "Byronic Hero" (Byron'vâri kahraman) adı verilen renkli bir edebi figür yarattığını belirtir. Byron'ın dandy yaşamının izleri ve özellikleri, Byronvâri kahramanlarda açıkça seçilir. Jerome McGann'ın çıarımına göre; “[B]yron'ın Romantizmi sadece politik bir güç değil aynı zamanda pür bir kişisel güçtür: Byron muhteşem bir âşık, politik değil erotik ilişkiler adamı, Naiplik dönemi İngiltere'sinin hoppa ve gösterişli dünyasının kırgın dandysi”dir (McGann, 2002, s.113). Byron'vâri kahramanlar da Byron'ın temsil ettiği kırgın dandy imajının edebiyata yansımış çeşitlemelerinden başka bir şey değildir.

Byron'ın yaşadığı dönemde, yüksek sosyetenin yerleşik değerleri klasik etkiler altındadır. $\mathrm{Bu}$ değerler üzerine giden Byron, Romantikler gibi bir çeşit karşıt-imaj yaratma yoluna gitmiştir. $\mathrm{Bu}$ bakımdan onun dandyliğinin, romantik akımın kaideleri ile şekillenmiş olduğu sonucu çıkarılabilir. Brummell ile başta yalnızca modaya ve sosyal yaşama içkin bir erkek tipolojisini imleyen pür dandy imgesi, Byron ile birlikte edebiyatın ve sanatın diğer dallarının kahramanı haline gelmiş; dandy imgesi romanlarda, şiirlerde, tiyatro oyunlarında ya da resimlerde, karikatürlerde ele alınan bir figüre dönüşmüştür. Böylece dandyler giderek modernleşme sürecini yaşayan Avrupa'nın kültürel ve sanatsal mecrasında bir değer kazanmaya başlamıştır.

Oscar Wilde (1854-1900), modernist özbilinci tanımlayan gerilimleri yansıttığı kabul edilen yaşam tarzı ve edebi yapıtlarıyla İngiliz dandyliğinin doruk noktasında bulunan kişidir. Oscar Wilde, dandy olarak yaşamış ve bu yaşantısıyla modern özne'yi gerçekleştirme gayreti içinde olmuştur. Oscar Wilde, sosyal yaşamında büyük bir üne kavuşmuştur. Bu ününü, İngiliz toplumunda bir moda halini alan dandylik eğilimini kendi görüşleriyle sentezlemesi neticesinde kazanmıştır. Wilde'ın dandyliğini açıklayan en doğru ifade "tutku”dur. Her daim "güzellik", "gençlik", "ün”, "retorik" ve "hemcins" aşkı gibi benliğine özgü tutkuları doyuma ulaştırmak için yaşadığını dile getiren Wilde'ın eserlerinin tamamında, benliğinde duyduğu bu tutkulara rastlamak mümkündür. Tutkuları içinde en büyüğü, ister "iyi" isterse "kötü" anlamda olsun, bir biçimde ünlü olmaktır. Wilde, bunu büyük oranda da başarmıştır. Wilde, her şeyi alaya alan yapısı ile arzu ettiği üne kavuşmak için kendinden yadsınamaz bir "gösteri adamı" yaratmıştır.

Oscar Wilde, sosyal yaşamında benimsediği dandy yaşam tarzının merkezine, "bireysel haz" ilkesini koyar. Hayatı boyunca kişinin tutkularını yaşaması gerektiğini savunur. Kendisi de yaşamının her anını tutkularını doyurmak için yaşar. Elisa Glick'in belirttiği gibi, Wilde'ın dandyliğini biricik kılan, erkek ile kadını net sınırlarla birbirinden ayıran egemen toplumsal cinsiyet kategorilerini sorgulayan ve takındığı dandy pozuyla doğal kabul edilen cinsel kimliklerin aslında birer toplumsal kurgu olduğunu gözler önüne sermesidir. $\mathrm{O}$, kitleleri hor görmüş ve her daim kitle kültüründen 
kaçmayı arzu etmiştir (Glick, 2001, s.140-143). Dandy yaşam tarzının estetizm akımının ilkeleriyle bütünüyle örtüşmesi dolayısıyla, Oscar Wilde 'estetik dandy' olarak adlandırılmıştır.

İngiltere' de gelenek ile modern arasındaki çelişkilerin birer ürünü olarak doğan dandy imgesi kendini daha çok sosyal yaşam dandyliği biçiminde göstermiştir. Diğer bir deyişle İngiltere'de dandylik bir yaşam tarzı olarak ortaya çıkmış ve gelişmiştir. Ancak daha sonra Fransa'da felsefi alt yapısını bulmuş olan dandylik, devrimin de etkisiyle asi bir hüviyete bürünmüş, geleneğe karşı estetik bir başkaldırı hareketine dönüşmüştür. Kendilerini kapitalist üretimin dışında tutan, fakat bilgi ve birikimleriyle toplumu değiştirme gücüne erişen entelektüeller olarak tanımlanmaya başlanmışlardır.

Modernitenin Fransa'da estetik başkaldırı hareketinin kahramanı olarak karşıladığı dandyler, en nitelikli halleriyle Baudelaire'in şiirinde ortaya çıkmıştır. Dandylik, Baudelire'in kuram ve pratikleriyle devrimci ve isyankâr sıfatlarını kazanmıştır. Ali Artun, Baudelaire'de Sanatın Özerkleşmesi ve Modernizm başlıklı makalesinde Baudelaire'in moderniteye ve modern çağın kahraman imgesine bakışını şu sözlerle özetlemektedir: Baudeliare 1846 Salonu üzerine yazısında $<$ Modern hayatın Kahramanlığı $>$ na değinirken sorar: Antik zamanların idealleştirilmesinden başka bir şey olmamasına rağmen, koca klasik geleneğin yıkılmasından sonra ne olacak? Endişeye yer yoktur; modern zamanlar da en az öncekiler kadar, <yüce temalara, destansı niteliklere ve kendine özgü güzellik formu>na sahiptir (Artun, 2011, s.11).

Baudelaire, modernizmi yeni bir toplumsal dönem olarak kabul etmiştir. Ona göre, modernizmin de kendine özgü güzellik biçimleri olmalıdır. Baudelaire'in modern kahraman kültü olarak öne sürdüğü kahramanlarından olan dandy, modernizmin kendine özgü güzellik biçimlerinden birini temsil etmektedir. Baudelaire'in dandysi sergilediği kamusal performansla "sanat için sanat" söyleminin modern hayattaki suretinin somut bir göstergesi olmuştur. Baudelaire için dandy muhalif ve isyankâr bir doğaya sahiptir. Baudelaire şöyle der: Dandylerin hepsi insan onurunun en iyi yönünün, bayağılıkla savaşma ve onu yok etme gibi günümüz insanlarında çok az rastlanan bir ihtiyacın temsilcileridir. Dandy'lerin, tam da soğukluğu nedeniyle tahrik edici olan bir zümrenin tepeden bakan, kibirli tavrı buradan kaynaklanmaktadır (Baudelaire, 2011, s.235).

Kişiliği gibi estetiğini de zıtlıklar aracılığıyla ören Baudelaire'in estetik bir tutum olarak benimsediği dandylik; sanatçının kalabalıklardan mest olan, kalabalıklar arasında seçtiği her kılığa girebilmenin hazzına kapılan kimliğinin zıddını temsil eder. Budelaire'in ele aldığı gibi; aristokrat edasıyla dandy, kalabalıklardan tiksinir. Kalabalıkların silikliği ve bayağılığı karşısında o, eşsiz ve yüce (sublime) olabilme kudretinin sembolüdür. Kılıktan kılığa girebilmenin fahişeliğinin aksine, dandy kimliğinde sanatçı -ve sanat- sadece kendisiyle ilgilidir (Baudelaire, 2011, s.27).

Sonuç olarak Baudelaire'in modenitenin yeni kahraman kültü olarak felsefi bir boyut kazandırdığı dandy fenomeni, tipolojik özellikleri bakımından; maddi imkânları olan, aristokrasi ile bir biçimde bağı olan, maddi varlıkları nedeniyle çalışma zorunluluğu olmayan, toplumda görülmek için kendini metalaştırırcasına baştan sona teşhir eden, aynı zamanda ince zevk sahibi, entelektüel birikime sahip ve ustaca konuşabilen, toplumu kışkırtan, güzel görünümlü, ince zevk ve ince sözle donatılmış erkeklerdir. Bohemlerin "hayatı" sanat eserine dönüştürme gayelerinden farklı olarak, Baudelaire'in düşüncesinde dandyler "kendilerini" sanat eserine dönüştürmeye çalışırlar.

Dandizetteler tarih sahnesinde belirdikleri andan itibaren en az dandyler kadar yaşadıkları toplumda olay yaratmışlardır. 1789'da ilan edilen İnsan Hakları ve Sivil Hakları Bildirisi'nden hemen sonra Olympe de Gouges'un 1791 yılında ilan ettiği Kadının ve Kadın Yurttaşın Haklar Bildirgesi 
(Gouges, 1791) dandy ve dandizettelerin modern toplumda boy göstermeye başladığ 1 yıllardır. Sivil hakların sadece erkekler için geçerli olduğu modern çă̆ın başlarında, kadınlar için aynı hakları ve yükümlülükleri talep eden Gouges'un bildirgesini hayata geçirecek olan kadın kahramanlar, bir tasarım olarak sunulan modern yaşamı bizzat deneyimleyen dandizetteler olmuştur.

Her çağ, kendi mitini yapacak ve yaşayacak kahramanlara ihtiyaç duymuştur. Aydınlanma'nın temel hedefleri içinde yer alan eşitlikçi hareketlerin kitlelere sunulması ve modernitenin geleneği alaşağı etme arzusuyla giriştiği sosyal yaşamı değiştirme/dönüştürme hareketleri kitleleri peşinden sürükleyecek kahraman ihtiyacını beraberinde getirmiş; kendilerini sanat eseri olarak kuran, yaşam tarzları ve estetik üretimleriyle ünlenen dandy ve dandizetteleri modern kahramanlık destanlarının yazarı ve yapanı haline getirmiştir. Bütünlüklü bir dandizette teorisi bulunmamasına rağmen, kadın İngiliz dandyleri olarak bilinen dandizettelerin ortaya çıkış dönemleri erkek dandylerle peş peşe olmuştur. Zamanlarının çoğunu dandylerle arkadaşlık ederek geçiren dandizettelerin yaşam tarzları ve tavırları tıpkı dandyler gibi şekillenmiştir. Kadın olmalarına rağmen bazı dandizetteler neredeyse erkek dandyler gibi giyinmiş, onlarınki gibi bir retorik geliştirmiş ve erkek dandylerin bir takım tipolojik özelliklerine bürünmüşlerdir.

Charles Dickens All The Year Round adlı eserinde on sekizinci yüzyıl sonlarının modern Batı Avrupa toplumlarında boy göstermeye başlayan ve kısa sürede kültürel ve estetik fenomen haline gelen dandyler ve dandizetteler için; “1819-1820'lerin dandy ve dadizetteleri garip bir yarış yapmış olmalı. 'Dandizette', giyim meraklısı kadınları tanımlamak için kullanılan bir terimdi ve onların absürdlükleri dandylerinkiyle tamamen eşitti” (Dickens, 1869, s.189) yargısında bulunarak dandy ve dandizettelerin toplumsal performanslarının eşanlamlı doğasına dikkati çekmiştir. Tıpkı dandylerinki gibi, dandizettelerin de bulunuş amaçları kendilerine işaret etmektir. Dandizetteler bunu başarabilmek için modernitenin geleneksel toplumu değiştirme/dönüştürme araçlarından biri olarak keşfettiği "moda" olgusunu zarif ve detaycı bir incelikle kullanmışlardır. Dandizetteler giyim kuşamlarından başlayarak her türlü yaşamsal etkinliklerini teatral bir icraya dönüştürmüş, bu yolla kendilerini bir sanat eseri gibi kurmayı başarmışlardır. Her yaptıkları, her düşündükleri, her konuştukları şey mutlaka incelikli bir kurgu ile tasarlanmış, ürettikleri estetik anlamlarla kendi biricikliklerini ilan etmişlerdir.

Modern çağın keskin virajlarından biri olan on dokuzuncu yüzyılın ikinci yarısında, Paris ve Londra metropolleri feminist hareketin ilk dönemlerini yaşamıştır. Bu hareketin öncülüğünü yapan ve politikaya, edebiyata, mertopollerde akıp giden sosyal yaşama, performans sanatları ile görsel sanatlara kendilerini vakfetmiş olan dandizetteler, kadın dandyizmi ve manifestolarının yaratıcısı olmuşlardır. Dandizetteler, Senem Yazan'ın belirtmiş olduğu üzere, tercihlerinden ötürü toplum tarafından dışlanma riskini göze alarak, Viktoryen ahlakın en katı biçimde sosyal yaşama hükmettiği bir dönemde erkek kıyafetleri ve aksesuarları, eril yaşam tarzı ve alışkanlıklarıyla etkileşime geçmişler; baskın Viktoryen söylemlere soğuk mizaçlılık, kinizm, kışkırtma gibi Naiplik dönemi dandysinin belirleyici özellikleriyle meydan okumuşlar; yaşam tarzlarının teatral sunumlarıyla, ataerkil toplum düzenine karşı, kültür ve seçimle şekillenmiş kadın maskülenliğini yaratmışlardır (Yazan, 2011, s.1). Diğer bir deyişle dandizetteler, dandylerin on dokuzuncu yüzyılda modernite içinde yer aldıkları kahraman rolünü, ilk dönem feminist hareketin sosyal, kültürel ve pratik katılımcıları olarak paylaşmışlardır. Dandizetteler de tıpkı dandyler gibi, kendi farklılıklarını toplumu aydınlatmak amacıyla icra etmeye adamışlardır. Kişisel hazları doyurma ve estetik icra, onların mevcudiyetini kanıtlayan yegâne olgu olarak göze çarpmıştır. 
Dandylerin ortaya çıtığı ilk dönemlerde benimsedikleri görsel stratejiyi kullanan dandizetteler, feminen bir imajla toplumda hızla yükselmiş; dandizetteler bu sayede aşamalı olarak dandynin konumunu ele geçirmişlerdir. Dandizetteleri marjinal kılansa; farklı yetişme tarzları, eğitimleri, sosyal statüleri ve cinsel tercihleri olmuştur. İlk dandizette hareketleri, erkek kiyafetlerini bir başlangıç olarak kullanan gruplar arasında başlamıştır. Bu gruplar kıtlık isyanlarında, muhalif gösterilerde veya teatral performanslarda ortaya çıkmıştır. Dandizettelerin birçoğu erkek kıyafetleri giymiş ve eril söylemleri sahiplenmiş; kıyafet tercihleri ve sansasyon yaratan sıra dışı yaşam tarzları, modernitenin ürettiği kültürel ortama kolektif bir karşılık önermiştir. Onlar için eril söylemler, kadın özgürlüğünün modern toplumdaki sunumu anlamını taşımıştır. Kimileri bilinçli bir politik seçim, kimileri ise salt bir kişisel estetik yaratma kaygısıyla erilliğin her yönünü kullanma yoluna gitmiş; kadın maskülenliğinin aykırı ve çok yönlü modelleri onlar tarafından oluşturulmuştur.

Modernitenin bir tür "yeni kadın” tasarımı olarak selamladığg dandizetteler, toplumsal yaşam katmanlarında adeta bir kimlik inşasına girişmişlerdir. Dandizettelerin en önemli kozu, toplumsal performanslarında teatralliği bilinçli ve sistematik bir dönüşüm aracı olarak kullanmalarıdır. Bir icra merkezi olarak sahne, on dokuzuncu yüzyılın sonlarında kültürel dönüşümün lokomotifi görünümdedir ve dandizettelerin kendilerini görünür kıldıkları ilk mecradır. Öyle ki, çağdaş moda tarzları ve yeni bir toplumsal cinsiyetin ortaya çıkışı ilk elden sahne aracılığıyla gerçekleşmiştir.1830'ların Paris'inde toplumsal cinsiyet hareketi sahnelerde ve sokaklarda aktrisler, kılık değiştirerek özgürce gezinmek isteyen kadınlar ve fahişelerce deneyimlenmiştir. Dandizetteler, kendilerine erkeklerle aynı platformda yer alacakları bir pozisyon aramışlardır. Bu pozisyonu elde edebilmek için, geleneksel kadın-erkek tanımlarını alt üst etme yoluna gitmişlerdir. Ataerkil düzene karşı giriştikleri mücadeleyi kazanabilmek için teatralliğin gücünü kullanmışlardır. Dandizetteler, günlük yaşam pratikleri içinde bilinçli ve sistematik biçimde oynamışlar; teatrallik aracılığıyla "Nasıl bir erkek olunur?" sorusunu, yaparak ve yaşayarak cevaplamaya girişmişlerdir. İşte dandizettelerin günlük yaşam pratiklerinin özniteliğini dramaya içkin kılan da bu tutumları olmuştur. Bu yeni kadınlar, erkek otonomisi ve otoritesinin sembollerini bir strateji olarak kullanmışlardır. Kültürel dolayımla tanımlanmış kadınlık ve erkeklik kategorilerinin yarattığı haksızlıklara göğüs germek, heteroseksüel dünyanın geleneksel rollerinden ve toplumsal beklentilerinden kaçmak, toplumda sadece erkeklere tanınan sosyal ve politik hakları kendileri için de elde etmek, ikili cinsiyet/toplumsal cinsiyet/arzu sistemini teatral bir sahnede bir performans olarak yapı bozuma uğratmak, erilliği iddia etmek ve bir erkek özne mevkisi olarak erkekliği kovalamak, anatomilerindeki tuhaflıklarda bir toplumsal cinsiyet kimliğine sahip olmak amacıyla kendilerine inanan cinsel uyuma işaret etmek için erkek kıyafetleri giymişlerdir. Dandizetteliği yaşam pratiklerinde deneyimleyen seçkin çevrelerdeki aristokratik Avrupalı kadınlar, sosyal yaşamlarında vuku bulan kayda değer maddi gelişmelerden ötürü fiziksel aktiviteleri benimsemeye başlamışlardır. Bu 1860'lardaki kriket sporuyla başlamış; 1870'ler ve 1880'lerde belirli bir kıyafet kombinasyonu gerektiren tenis, okçuluk, yatçılık, avcılık, atıcılık vegolfe girişle devam etmiştir (Yazan 2011, s.5).

Cüretkâr ve soğuk mizaçlı olmasının yanı sıra; bir erkek gibi küfreden, kumar oynayan, içki içen, cinsel hazzı dışa vurma biçimlerinden dolayı erkeği ve kadını birbirinden ayıran sahaları bölerek heteroseksüel ayrımın üstesinden gelen fahişe, modernitenin moda ve meta kültürü tarafından sürdürülen tehlikeli cazibesini temsil ederken; ötekinin doğasına içkin ve toplumsal cinsiyetin de ötesinde bir yaratık olmuştur. Kadın dandyliği de "bir gösteri yaratı̆̆ı, bir kamusal haz nesnesi" (Baudelaire, 2011, s.37) olan 1860'ların fahişe figüründe bulduğu geleneksel rollere başkaldırı 
noktaları sayesinde gelişmeye devam etmiş ve on dokuzuncu yüzyılın sonlarına doğru toplumsal cinsiyet tartışmaları üzerinden daha fazla biçimlendirilmiştir.

Dandizette fenomeni 1860'ların sonunda ortaya çıkmaya başlamış, en büyük popülerliğine 1. Dünya Savaşı'ndan önce Britanyalı akrist Vesta Tilley (1864-1952) ile ulaşmıştır. Bir kadın olarak Tilley, gerek sahne üzerinde gerekse kamusal alanda maskülenliği kendi kadınlığına ek olarak yapılandırmak için o dönem tamamı erkeklere ait olan ve erkeklikle ilişkili karşı cins kıyafetlerini, karşı cins pozlarını ve aksesuarlarını kullanmıştır. Giyim kuşam hususunda asil bir duyu geliştirmiş olan Tilley kamusal alana çıkarken kendisine, sosyetenin büyük bir kısmı üzerinde kasti olarak katı bir mesafe yaratan dandy kimliğini yakıştırmıştır. Tilley'nin hafif figürü ve becerisi sadece mimikten ibaret değildir, aynı zamanda seyircinin imgeleminde var olan birçok satıcının, mağaza asistanının ve diğer alt-orta sınıf erkeğinin bedeninde konumlanan Viktoryen erkeklik tasarımlarını takip eden bir idoldür (Banville 2008, s.112-142). Müzikhol sahnesindeki Tilley'nin erkeklik performansları ve onun sahne dışında kalmış kadınlık performansları Judith Halberstam'ın ifade ettiği “kadın maskülenliği”" deyiminde ve Viktoryen maskülenliğinin genel çerçevesi içinde yer alır. Gece kıyafetleri içindeki müzikhol dandysi, 1880-1920 yılları arasında androjen marjinal kahramana dönüşmüştür. Müzikhol dandysi görünümündeki dandizette tasarımı; tek camlı gözlük, baston, kravat ve sigara gibi erkek sembollerini özenle sahiplenmiştir. Bu yolla yaratılan bir lezbiyen kimliği, daha sonraki yıllarda Anglo-Amerikan kadın mirasına materyal sağlayacaktır (Yazan, 2011, s.6-7).

Dandizetteler, Amerikalı ressam Romaine Brooks (1874-1970) ve İngiliz yazar Radclyffe Hall (1880-1943)'ün ürettikleri sanat eserlerinde kahramanlaşmıştır. Brooks çalışmalarında yer verdiği kadın dandy sembolizmini, tüm eril durağanlığa başkaldıran lezbiyen arzunun açık bir göstergesi olarak ele almıştır (Lucchesi, 2001, s.153-58). Brooks dandynin “eril” kültürel çağrışımlarını yirminci yüzyılın ilk dönemlerinin Paris ve Londra'sında "dişil” homoerotik bir cinselliğe dönüştürmüştür (Weeks, 1977, s.88). RadclyffeHall ise; The Well of Loneliness adlı romanında 1828'de kamusal olarak savunmak zorunda kaldığı, cinsel açıdan alt üst edilmiş kahraman Stephen'1 yarattı. Bu romanın kahramanı, geleneksel, politik ve sosyal kategoriler ile modernitenin Yeni Kadın tasarımının eziyet verici pozisyonu arasında cisme bürünmüştür.

Özetle, özerklik ve otorite sembolleriyle erkek kıyafetini benimseyen modernitenin kadınları kendi kültürel tarihlerinde, erkek maskülenliğinden özellikle ayrılmış yeni bir toplumsal cinsiyet yaratmışlardır. On dokuzuncu yüzyıla kadar verili söylem tarafından biçimlendirilen, kadınların adı geçen yüzy1ldaki hak mücadelesi ve bu mücadeleyi sürdürme biçimleri geleneksel toplumsal cinsiyet kategorilerini alt üst etmeyi başarmıştır. Modernitenin "yeni kadın” diye selamladığı dandizetteler bu başarıyı, gerek eğlence dünyasında gerekse kamusal alanda sergiledikleri teatral performanslarla elde etmişlerdir. Bugün dramanın tanımında karşılaştı̆̆ımız "yaparak ve yaşayarak öğrenme” modeli, dandylerle eşzamanlı olarak tarih sahnesinde belirip, 1860'larda dandylerin konumlarını ele geçiren dandizettelerin teatral performanslarında vücut bulmuştur. Dandizetteler, yeni toplumsal cinsiyet kategorisini “yaparak ve yaşayarak” öğrenmişler, kitlelere de "yaparak ve yaşayarak” öğretmişlerdir. Modernitenin nimetlerini sonuna kadar kullanan bu marjinal kadınlar, mitik dünyanın amazonları gibi ataerkil düzene başkaldıran kadın kahraman imajını modern çağda kendi bedenleri ve yaşam pratikleri üzerinden yaratmayı başarmışlardır. Danzidetteliği bu yolla deneyimlemiş isimler arasında Lady Blessington, Marchesa Casati, C. Z. Guest, Coco Chanel, Tamara de Lempicka ve Marlene Dietrich’i örnek göstermek mümkündür. 


\section{Kaynakça}

Artun, A. (2011). "Baudelaire'de Sanatın Özerkleşmesi ve Modernizim”, Charles Baudeliare, Modern Hayatın Ressamı içinde, Çev.: Ali Berktay. İstanbul: İletişim Yayınları.

Banville, S.(2008). "The Daily Male: VestaTilleyandThePerformance of Masculinity on the Victorian Music-HallStage", Hunks, Hotties, andPrettyBoys: Twentieth Century Representations of Male Beauty, Davis, S.L andMaglina, L. (eds.), Cambridge Scholars Publishing.

Baudeliare, C. (2011). Modern Hayatın Ressamı (A. Berktay, Çev.). İstanbul: İletişim Yayınları.

Çabuklu, Y. (2008). “DandidenMetroseksüele”, Toplumsal Performanslar Ankara: Ayraç Kitap+Evi.

Dickens, C. (1869). "CaricatureHistory”, AllTheYearRound, Vol. 1, Jan.28, London.

Glick, E. (2001). "TheDialectics of Dandyism", CulturalCritique, No. 48.

Hazlitt,W. (1934). "TheDandy School”, The Complete Works of William Hazlitt, London: Dent.

Küçük, M. (1994) “Postmodernin Modern Karakteri ya da Dönemleştirmenin İronisi”, ModerniteVersusPostmodernite, Ankara: Vadi Yaylnlart.

Longman Dictionary of Contemporary English, (2005). Edinburg: PearsonEducation Limited.

Lucchesi, J. (2001). “TheDandy in Me”, Dandies: FashionandFinesse in Art andCulture, Yeh, S.F. (ed.), New York: New York UniversityPress.

McGann, J. (2002). Byron andRomanticism, Ed.: James Soderholm, Cambridge: Cambridge UP.

Weeks, J. (1977). ComingOut, HomosexualPoliticsIn Britain, From 19th Century ToThePresent, London: Quartet Books.

Yazan, S.(2011), FemaleDandyism: DefianceorDeference?,University of theArtsLondon, LondonCollege of Fashion.

\section{İnternet Kaynakları}

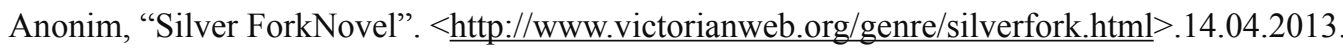

De Gouges, O. (1990). Kadının ve Kadın Yurttaşın Haklar Bildirgesi, Metnin alındığı kaynak: UteGerhard,GleicheüohneAngleichung,Munchen, VerlagCM. Beck, 1990, s.263-269'den çev.: Ece Göztepe, http://dergiler.ankara.edu.tr/dergiler/38/297/2716.pdf, 04.11.2013.

Van Dooren, T. (2011). FromBrummellto Byron: TheStory of EarlyNineteenth-Century British Dandyism, $<$ http://www.scriptiebank.be/.../81165dd4c8339159c1d47961d38d7ff6.pdf $>20.03 .2013$. 